\title{
CONCEITO MODERNO DA "DOENÇA DE DUPLAY"
}

\author{
J. P. Mancon Des DE SOUza
}

Este trabalho pretende fazer uma atualização quanto às afeç̧ões têndino-capsulares do ombro, e aparece nesta coletânea de trabalhos neurológicos, porque freqüentemente o neurologista se vê diante dêstes problemas. O têrmo "doença de Duplay" deve ser abandonado porquanto o que pretende significar não passa de um episódio na evolução de um conjunto de entidades mórbidas já bem diferenciadas. Vamos expor cada uma destas no seu conceito patológico, nos seus dados semiológicos e no que tange à orientação terapêutica.

As contribuições de Duplay ${ }^{1}$, a partir de 1872, representam o primeiro esfôrço para separar as lesões periarticulares do ombro, do grupo geral das artrites. Criando o têrmo periartrite, Duplay pretendeu demonstrar que o processo inflamatório da bôlsa serosa "subacrômio-deltóidea" era. essencialmente, uma lesão extra-articular. Êstes relatos foram anteriores ou coincidentes com a descoberta dos raios $X$, de modo que Duplay não teve elementos para distinguir os casos de periartrite com ou sem depósito calcáreo.

No início do presente século, demonstrou-se a existência de deposições calcáreas com o auxílio dos raios $\mathrm{X}$, tanto em ombros dolorosos como em assintomáticos; a remoção cirúrgica de tais depósitos foi proposta para alívio da dor por Painter (1905), Baer (1907), Bergemann e Stieda (1908), todos citados por Howorth ${ }^{7}$. Entretanto, a maior parte dos médicos obstinadamente se recusava a aceitar qualquer distinção entre ombro doloroso com depósito calcáreo e aquêle sem tal deposição, continuando, de outro lado, a usar o têrmo periartrite para descrever as mais variadas condições patológicas do ombro.

Entre nós persiste o conceito simplista segundo o qual o caso de ombro doloroso no qual a radiografia mostre sombra calcárea deve ser diagnosticado como doença de Duplay e tratado pela röntgenterapia profunda.

Devemos realçar as idéias de Codman, que teve o mérito de separar as várias entidades patológicas que afetam o ombro, através de uma série de trabalhos fundamentais que culminaram em magnífico livro ${ }^{2}$. Codman descreveu, não só as roturas do supra-espinhoso, mas também a exata localização e o significado das deposições calcáreas. 0 conceito por êle criado é hoje aceito em sua quase totalidade, tendo já obtido confirmação por estudos em cadáveres (Keyes ${ }^{3}$ ), estudos de ordem experimental (Wilson ${ }^{4}$ ), assim como clínicos (Steindler ${ }^{5}$ e Howorth ${ }^{6}$ ) e operatórios (Watson-Jones ${ }^{7}$, Mc Laughlin e Asherman ${ }^{8}$, Moseley ${ }^{9}$ ). 
Vamos expor, resumidamente, a anatomia e a fisiologia do ombro e as condições clínicas mais freqüentemente aí encontradas, procurando base em conceitos já firmados e aceitos pelas mais destacadas escolas ortopédicas.

\section{ANATOMIA E FISIOLOGIA DO OMBRO}

() tendões dos músculos subescapular, supra-espinhoso, infra-espinhoso e pequeno redondo inserem-se diretamente na cápsula da articulação escápulo-umeral, formando bainha espêssa e contínua cuja face ventral corresponde ao teto da articulação escápulo-umeral e cuja face dorsal está em contacto com a bôlsa serosa subacromial. Esta bôlsa se estende por haixo do deltóide até sob o acrômio e ligamento córaco-acromial, separando, portanto, o m. supra-espinhoso de quaíquer atrito com o acrômio e o $\mathrm{m}$. deltóide. Normalmente, a bôlsa subacromial é hemisférica, transparente, de paredes finas, com um diâmetro de 4 a $5 \mathrm{~cm}$ e não se comunica com a articulação escápulo-umeral; quando, na dissecção em cadáver, se encontra comunicação entre a bôlsa e a articulação, ela é o resultado de uma rotura do $\mathrm{m}$. supra-espinhoso acompanhada de fenda no assoalho da bôlsa. As fibras do $\mathrm{m}$. intra-espinhoso se entrelaçam tão intimamente com as do $\mathrm{m}$. supra-espinhoso no ponto de inserção de ambos na cápsula, que nem microscòpicamente se diferencia cápsula de tendão. $O$ sulco intertubercular que recebe o tendão bicipital, na posição anatômica, jaz lateralmente à linha mediana do braço. Sua situação varia, naturalmente, com o grau de rotação do braço.

No movimento de abdução do braço tomam parte ativa os ms. deltóide e supra-espinhoso. Se só agisse o deltóide, a cabeça umeral tenderia a escapar por cima, sôbre a fossa glenóide; entretanto, o supra-espinhoso, tracionando transversalmente, mantém as superfícies articulares em contacto, impedindo que isto aconteça (fig. 1). E' por êste mecanismo que as roturas do supra-espinhoso interferem com o movimento de abdução do braço.
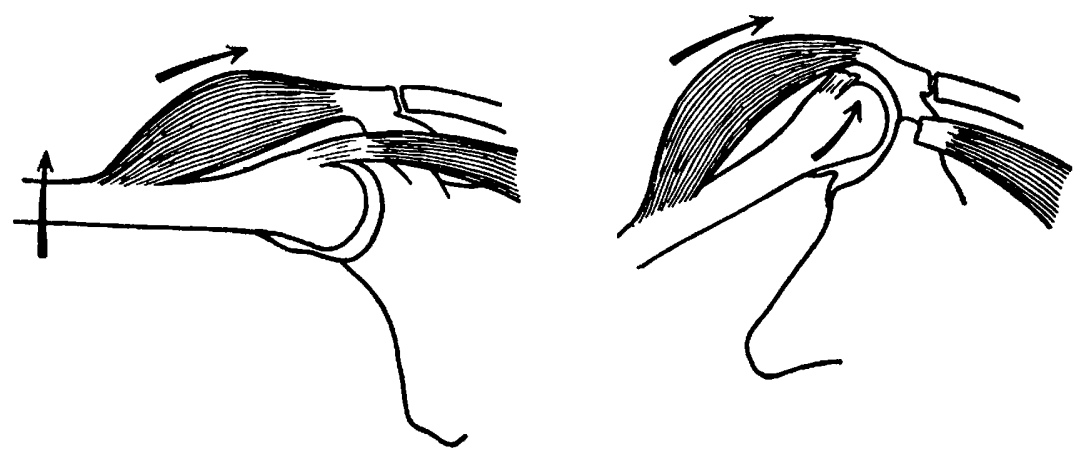

Fig. 1 - O músculo supra-espinhoso fixa a cabeça do úmero, enquanto o deltóide executa a abdução. Se houver rotura do supra-espinhoso, o mais que se consegue é fraca abdução até $60^{\circ}$, pelo movimento de báscula do osso escapular (esquema imitado de Watson-Jones).

A abdução completa só é possível com o úmero em rotação externa. Com o úmero em rotação interna, a abdução não vai além de 90 , exceção feita das crianças. O ponto crítico da abdução é entre $60^{\circ}$ e $120^{\circ}$, correspondendo à zona de maior atrito entre m. supra-espinhoso e acrômio, separados pela bôlsa subacromial. 
Duplay, ao estudar a etiologia da periartrite, reconheceu, como causa primeira, um traumatismo mais ou menos violento. Embora o aceitemos ainda hoje como um dos elementos causais, o traumatismo, por si só, dificilmente é suficiente, sendo necessária a pré-existência de um fator degenerativo. De acôrdo com êste conceito e seguindo a classificação de WatsonJones, dividimos as lesões têndino-capsulares em: 1) tendinite do supraespinhoso e bursite subdeltóidea; 2) rotura do tendão do supra-espinhoso; 3) afecções do tendão longo do bíceps; 4) formação periarticular de aderências (ombro congelado).

1. Tendinite do supra-espinhoso e bursite subdeltóidea - Os microtraumas repetidos conseqüentes ao uso do braço e, principalmente, à realização de bruscos movimentos de abdução e de rotação, provocariam, pelo atrito, distúrbios circulatórios que seriam os responsáveis pelo desenvolvimento de lesões degenerativas. $0 \mathrm{~m}$. supra-espinhoso seria particularmente atingido porque é estrutura de recente aquisição filogenética. 0 trauma único representado por uma contusão ou uma entorce poderia também favorecer o desenvolvimento de idênticas lesões degenerativas.

Calcificação de tendões ou ligamentos é ocorrência comum depois de lesões traumáticas, sendo interpretada como secundária à necrose. E' por processo semelhante que se depositam sais de cálcio nas fibras gastas e necrosadas do $\mathrm{m}$. supra-espinhoso.

Enquanto os depósitos calcáreos estão difusamente espalhados peło tendão êles são silenciosos, mas quando chegam a constituir uma elevação pelo acúmulo de grânulos, aparecem sintomas dolorosos. Esta elevação pode seguir dois caminhos: 1) perfurar o assoalho da bôlsa, sendo as partículas de cálcio absorvidas no líqüido fibrinoso, a que constituiria um processo de cura; 2) não provocar perfuração e neste caso os sintomas dolorosos continuam indefinidamente, provocando limitação de movimentos e possibilitando a formação de aderências e a constituição de "ombro congelado".

A bursite calcárea é quase sempre secundária à tendinite calcárea. Os depósitos de fosfato e carbonato de cálcio como corpos estranhos, que irritam tanto o tendão como a bôlsa, são os responsáveis pelos sinais inflamatórios. Pode existir bursite subacrominal, secundária a distensão do ombro com derrame e hemorragia; durante a organização do hematoma formam-se extensas aderências dentro da bôlsa, de modo que qualquer contração do deltóide ou dos ms. rotadores do braço provoca dor e o movimento será concêntricamente limitado.

Quando, pela exploração, se encontra uma bôlsa intacta, lisa e homogênea, a única lesão de que se pode suspeitar é a de torção no tendão do bíceps. Quando se encontra a bôlsa avermelhada, edematosa, é sinal de que algumas fibras do supra-espinhoso se romperam ou que depósitos calcáreos romperam o assoalho da bôlsa. 
O conteúdo da cavidade pode variar desde o aspecto leitoso até 0 cremoso ou granular, como areia. A cavidade pode estar variàvelmente septada e, como ela jaz no tendão, as fibras dêste estão amolecidas, enroladas e sem brilho. Osso desnudo pode ser visto na base de algumas das cavidades. Estes depósitos podem ser encontrados também nos tendóes do $\mathrm{m}$. infra-espinhoso e pequeno redondo, sendo raro tal achado nos tendóes do subescapular e do bíceps.

Os sintomas dolorosos não são proporcionais ao tamanho, forma, número e densidade dos depósitos calcáreos, podendo haver dor mesmo na ausência de depósitos. E' provável que a tensão do material calcificado seja o principal responsável pela dor. Há pouca correlação entre o quadro clínico e o radiológico. A doença pode ocorrer em três estágios: agudo, crônico e latente.

Dor na região deltóidea é comum, irradiando-se para baixo até o antebraço; o ponto mais sensível se localiza no quadrante ântero-lateral do omb:o quando o supra-espinhoso está comprometido, no lateral quando se tratar do infra-espinhoso e no posterior quando fôr lesado o pequeno redondo. O movimento mais difícil de ser executado é o de abdução, principalmente entre $60^{\circ}$ e $120^{\circ}$. Às vêzes a dor é tão intensa que o movimento possível não ultrapassa de $10^{\circ}$, levando a pensar em rotura do supra-espinhoso. Os depósitos calcáreos são melhor evidenciáveis pelo exame radiográfico em varias posições: com o braço em posição indiferente, com rotação externa e abdução de 45 e $90^{\circ}$ e com rotação interna de $45^{\circ}$. Estas posições colocam os tendões do m. infra-espinhoso, supra-espinhoso, subescapular e bíceps em posição tangencial à cabeça umeral, demonstrando me. lhor não só as calcificaçốes como sua localização.

Em nossa experiência a melhor forma de tratamento consiste na injeção de procaína a $10 \%$ no ponto mais sensível, que, em geral, corresponde à inserção do supra-espinhoso no tróquiter. Desta maneira, pode-se. além da injeção, praticar a aspiração da calcificação, podendo-se usar duas seringas para injetar, lavar e aspirar as partículas de cálcio (Patterson e Darrach ${ }^{10}$ ).

Quando na fase aguda se mostra insuficiente a novocainização, Moseley recomenda a evacuação cirúrgica do depósito, método com o qual obteve resultados muito satisfatórios. Também nas fases subaguda e crônica pode ser empregado o tratamento cirúrgico, se bem que os resultados não sejam tão satisfatórios por causa das aderências e das contraturas pré-existentes.

A dor é provocada pela tensão e inflamação da bôlsa subacromial vizinha, de modo que todo processo que diminua a tensão e a hiperemia diminuirá a dor. Assim. Moseley propôs as compressas frias, com as quais obteve sucesso nos casos agudos, que passam, então, a subagudos ou crônicos. Compressas quentes e diatermia podem ser usadas com a finalidade de obter hiperemia ativa que torne possível a absorção do depósito. Com idêntico objetivo é recomendada a röntgenterapia, que não dissolve o cál- 
cio, mas que induziria hiperemia, provocando reabsorção da fibrina e do calcáreo (Steen e Mac Cullough ${ }^{11}$ ). Estes processos podem levar à cura mas são freqüentes o aumento da dor nos primeiros dias de tratamento, a cura incompleta e a recidiva.

Ultrapassando o estádio agudo, recomendam-se movimentos ativos para a recuperação daqueles músculos que estavam em espasmo. Entre os mais importantes, citamos os movimentos pendulares de Codman (fig. 2) e os com polias (Moseley). O efeito benéfico da mobilização ativa vem sendo assinalado desde Duplay, o qual recomendava exercícios metódicos e graduados e eletricidade aplicada aos músculos deltóide, supra e infra-espinhoso.

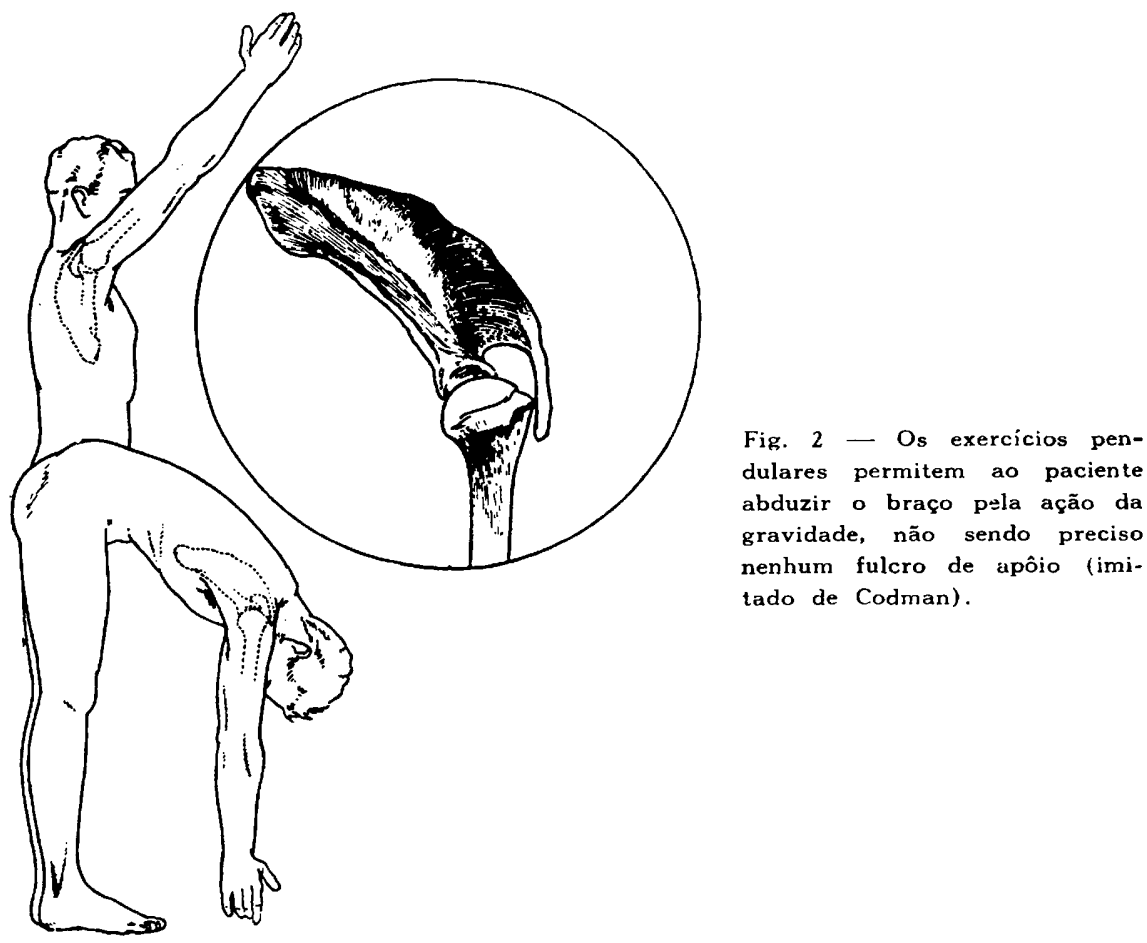

Nos casos operatórios em que a bôlsa subacromial é encontrada engrossada e com aderências, Moseley recomenda sua extirpação. Se os movimentos ativos são começados imediatamente após a operação, não haverá rigidez e presume-se que uma nova bôlsa se forme.

2. Rotura do tendão do supra-espinhoso - Nos casos recentes, trata-se em geral de pacientes de mais de 40 anos, trabalhadores braçais que, depois de torções graves ou de quedas, sentem dôres agudas, com incapa- 
cidade para abduzir o braço. As radiografias são negativas e não há limitação de movimentos quando os pacientes se mantêm com o tronco inclinado e os braços pendentes. Ao exame, os pacientes são incapazes de abduzir o braço acima de $80^{\circ}$, havendo um ponto doloroso e um sulco na zona de inserção do supra-espinhoso. A abdução passiva pode ser realizada sem dor e há queda do braço quando o suporte é retirado. Se, apesar da injeção de novocaína a $1 \%$, o braço não puder ser mantido acima de $90^{\circ}$, pode-se diagnosticar rotura, com certeza. A rotação do úmero transmitirá uma sensação de crepitação ao dedo do examinador.

Em casos antigos a dor melhora depois de alguns dias, mas a função permanece deficitária. Superpõem-se, então, atrofia dos músculos supra e infra-espinhoso e contratura dos adutores e rotadores internos, provocada esta última, principalmente, pelo uso de tipoia.

O tratamento de escolha consiste na reparação cirúrgica da rotura, a qual é praticada através de uma incisão transacromial. A osteotomia do acrômio é recomendada para facilitar a exploração cirúrgica, o tempo de sutura (particularmente difícil nas roturas antigas) e a recuperação no pós-operatório (Watson-Jones, Moseley).

A rotura do supra-espinhoso pode ser acompanhada de roturas do $\mathrm{m}$. infra-espinhoso, do subescapular ou do pequeno redondo. Elas deverão ser sistemàticamente procuradas e reparadas.

3. Afecções do tendão longo do bíceps - 0 tendão longo do bíceps se estende da fossa supraglenóidea, através da superfície articular da cabeça umeral, envolvido em uma baínha sinovial, ao túnel ósseo constituído pelo sulco intertubercular. Éste tendão só deslisa na baínha durante os movimentos da articulação escápulo-umeral, ou melhor, é o úmero que se move sôbre o tendão fixo durante os movimentos da articulação escápuloumeral. Não há movimento do tendão quando o bíceps se contrai para fletir e supinar o antebraço sôbre o braço (Lippmann ${ }^{12}$ ).

A maior excursão do bíceps é produzida quando as seguintes posições são alternadas: 1) o tendão é puxado para cima pela e.evação, rotação interna e flexão para frente do braço; 2) o tendão é puxado para baixo pela flexão para trás (extensão do cotovêlo) e rotação externa com o braço abaixado.

De acôrdo com Moseley, dividimos os processos bicipitais em: a) tendinite e tendo-sinovite; b) rotura parcial ou completa do tendão; c) deslocamento do tendão.

a) Tendinite e tendo-sinovite - $\mathrm{O}$ sintoma principal é constituído pela dor na face ântero-lateral do ombro, associada a espasmo muscular do trapézio, do deltóide, dos escalenos e até dos músculos do antebraço. $\mathrm{O}_{\mathrm{s}}$ movimentos podem estar limitados em tôdas as direções, sendo mais comprometidas a abdução e a rotação externa. Com o cotovêlo fletido a $90^{\circ}$, o paciente procura fazer a supinação do antebraço contra a resistência 
do observador: no caso de tendinite ou tendo-sinovite, o paciente acusa dor na fenda bicipital (sinal de Yergason positivo). Lippmann, em 12 casos operados, encontrou infiltração inflamatória, edema, degeneração da sinovial e de fibras colágenas da baínha sinovial e modificações proliferativas nos casos de doença muito avançada. $O$ tratamento nas fases aguda e subaguda consiste em repouso e aplicação de raios infravermelhos ou diatermia; a intervenção cirúrgica, recomendada nos casos de longa duração, consiste na abertura da baínha e libertação do tendão.

b) Rotura parcial ou completa do tendão - Os mesmos fatôres predisponentes descritos para a rotura do supra-espinhoso também aqui entram em ação, a saber: as modificações degenerativas e traumatismos repetidos, além dos efeitos da friç̧ão que provocam desgaste gradual do tendão (Meyer, cit. por Lippmann ${ }^{12}$ ). A rotura pode dar-se num ponto alto junto da glenóide ou na área capsular e num ponto baixo junto da corrediça bicipital. Pela inspeção, o corpo do músculo aparece proeminente e repuxado para baixo se a rotura fôr na porçáo proximal do tendão e repuxado para cima se a rotura ocorrer na parte distal do tendão. $O$ sinal de Yergason é quase sempre positivo. Nos casos de rotura aguda estará indicada a intervenção operatória, pois pode haver considerável perda de fôrça. Por uma incisão anterior o tendão rompido é suturado à curta porção do bíceps ou ao próprio sulco intertubercular. A porção intra-articular do tendão é ressecada. A reeducação de movimentos deve começar depois de três semanas.

c) Deslocamento do tendão - 0 deslocamento da longa porção do bíceps ou luxação foi bem estudado por Hitchcock e Betchtol ${ }^{13}$, em quatro casos comprovados cirùrgicamente; êstes autores mostraram que a saliência supratubercular de Meyer e uma fenda bicipital rasa associadas a vários fatôres que provocam um gradual deslocamento do tendão na direção medial, podem provocar friç̧ão, desgaste e ulterior deslocamento do tendão. 0 deslocamento do tendão bicipital pode ser diferenciado da tendinite pelo teste de Abbott e Saunders (cit. por Hitchcock e Bechtol ${ }^{13}$ ): depois de abdução completa do ombro, o braço que está em comp'eta rotação externa é, lentamente, trazido para baixo no plano da escápula; um ressalto palpável ou, mesmo, audível e muitas vêzes doloroso, é notado quando o tendão se desloca da fenda. 0 tratamento é operatório, consistindo na reinserção do tendão no sulco, sendo ressecada a porção do tendão que está acima.

4. Formação periarticular de aderências (ombro congelado) - 0 têrmo periartrite, empregado por Duplay na mais ampla acepção, vem sofrendo restrições pela identificação de vários grupos, c'aramente diferenciados, como o dos depósitos calcáreos, o das roturas do supra-espinhoso, o das lesões por atrito do bíceps, etc. Hoje êsse têrmo ainda é usado para significar diversas afecções, sendo que alguns autores o reservam para os casos em que há rigidez por aderências de variável intensidade. Julgamos 
que o têrmo deve ser abandonado ou sòmente empregado genérica e temporàriamente para significar ombro doloroso enquanto se aguarda diagnóstico definitivo.

A formação de aderências ou rigidez ou ancilose fibrosa pode ocorrer numa série de condições: 1) gerais (doenças cardíacas e pulmonares, fadiga, pacientes hemiplégicos e parkinsonianos); 2) químicas (depois de prolongada irritação por depósitos calcáreos, associada ou não ao emprêgo de raios X); 3) traumáticas: a) depois de luxações, fraturas e operações do ombro em pacientes idosos, longamente imobilizados; b) depois de roturas tendinosas ("rotator cuff") por muito tempo imobilizadas; c) depois de trauma ao conjunto tendão bicipital-baínha; 4) reflexas, do tipo Sudeck (depois de pequeno trauma em qualquer ponto da região do ombro ou do cotovêlo, antebraço e punho, inicia-se um processo agudo de atrofia óssea).

A síndrome do ombro congelado é caracterizada pela seguinte sequiência: 1) dor intensa no ombro, descendo pelo braço em seguida a um trauma de vária intensidade, num paciente de 50 a 60 anos; 2) a dor persiste e o movimento escápulo-umeral diminui até cêrca de $20^{\circ}$; 3) a dor diminui mas a rigidez persiste; 4) a dor continua diminuta e o movimento volta lentamente. Este ciclo pode durar seis meses a dois anos ou persistir indefinidamente na fase de rigidez.

Estes casos, quando operados, mostram: engrossamento e edema da bôlsa subacromial, com ou sem aderências; vascularização e espessamento da baínha dos tendões ("musculo-tendinous cuff"); o tendão do bíceps avermelhado, franjado; a cápsula aderente ao osso, mostrando-se inflamada ou fibrótica (capsulite de Withers ${ }^{14}$ ); podem-se encontrar roturas incompletas do supra-espinhoso, sendo que êste músculo quase sempre se mostra degenerado.

Simmonds ${ }^{15}$ julga que a lesão degenerativa do supra-espinhoso é o fator fundamental e que êste, constantemente irritado contra o acrômio, transmite às estruturas vizinhas (cápsula, baínha tendinosa, tendão bicipital) reações inflamatórias; estas estruturas, também pela falta de uso, se tornam inelásticas, com conseqüente perda do movimento em tôdas as direções a partir do ponto imobilizado. A cura poderia se dar pela absorção das áreas necróticas num tendão que se revascularizasse.

No que toca ao tratamento, deve-se, inicialmente, fazer a prova da anestesia, como recomendam Withers e Simmonds: se houver relaxamento, a limitação de movimentos era devida a espasmo muscular e provàvelmente a doença estaria numa fase de inflamação aguda e de exsudação, dentro e ao redor da cápsula; se não houver relaxamento, continuando a limitação de movimentos, a doença estariạ numa fase crônica, adesiva, com aderências fibrosas tanto intra como extra-articulares. Nestes casos, Simmonds recomenda a exploração cirúrgica com excisão completa do processo acromial e da porção articular do tendão bicipital, seguidas de manipulação; ulteriormente, fisioterapia para recuperação da fôrça muscular. 
Moseley recomenda a infiltração do espaço subdeltóideo com 50 a 60 $\mathrm{ml}$ de novocaína a $0,5 \%$ ou $1 \%$ e, depois, manipulação gradual muito cuidadosa; a seguir, exercícios com a polia para melhora da fôrça muscular.

Em conclusão, nossos conhecimentos já são satisfatórios quanto aos primeiros três grupos de lesões têndino-capsulares que estudamos. Quanto ao último capítulo, de "ombro congelado", expressão criada pelos autores inglêses e americanos, que se refere a uma entidade de origem obscura e variável, sôbre a qual nossos conhecimentos ainda são limitados. E' recomendável seu estudo para possível identificação de novos grupos patológicos.

\section{RESUMO}

O autor procura demonstrar que o têrmo "periartrite", criado por Duplay, é impróprio, já que esta condição, em geral, constitui parte apenas de lesões que, na sua maioria, são bem diferenciadas. Depois de breve apanhado anátomo-fisiológico, divide as lesões do ombro em: 1) tendinite do supra-espinhoso e bursite subdeltóidea; 2) rotura do tendão do supraespinhoso; 3) afecções do tendão longo do bíceps; 4) formação periarticular de aderências; "ombro congelado".

A respeito de cada um dêsses grupos faz considerações de ordem etiopatológica, clínica e terapêutica, realçando, nesta última parte, a importância da novocainização, da prova da anestesia, da exploração cirúrgica pela via transacromial e dos exercícios pendulares cuidadosamente realizados sob direta orientação do médico.

\section{SUMMARY}

The author tries to demonstrate that the term "periartritis" created by Duplay is improper, since this disease is generally part of several different lesions only. After brief considerations on anatomo-physiology of the shoulder. the author summarizes the lesions of shoulder as follows: 1) tendinitis of supraspinatus and sub-deltoid bursitis; 2) rupture of supraspinatus tendon; 3) lesions of the long tendon of biceps; 4) formation of periarticular adherences, "frozen shoulder".

He studies each group in its pathogenic, clinical and therapeutic point of view emphasizing the importance of procaine injection, anesthetic test, and surgical exploration by the transacromial via and the physiotherapy carefully supervised by the orthopedist.

\section{BIBLIOGRAFIA}

1. Follin, E. e Duplay, E. - Traité F́lémentaire de Pathologie Exierne, tomo 7. Masson et Cie., Paris, 1888. 2. Codman, E. A. - a) The Shoulder. Edição particular, Boston, 1934; $b$ ) Rupture of the supraspinatus. Am. J. Surg., 42: 
603-626 (dezembro) 1938. 3. Keyes, E. L. -- Observations on rupture of the supraspinatus tendon. Ann. Surg., 97:849-856, 1933. 4. Wilson, C. L. - Experimental degeneration of the supraspinatus tendon. J. Bone a. Joint Surg., 30-A: 769-778 (julho) 1948. 5. Steindler, A. - 'The 'Traumatic Deformities and Disabilities of the Upper Extremity. Ch. 'Ihomas ed., Springfield, 1946. 6. Howorth, M. B. - A Textbook of Orthopedics. Saunders, Philadelphia, 1952. 7. WatsonJones, R. - Fraturas e Lesões Articulares. 'I'rad. brasileira. Editora Guanabara, Rio de Janeiro, 1945. 8. McLaughlin, H. L.; Asherman, E. G. - Lesions of musculo-tendinous cuff of shoulder: some observations based on results of surgical repair. J. Bone a. Joint Surg., 33-A:76-86 (janeiro) 1951. 9. Moseley, H. F a) Shoulders Lesions. Ch. 'Thomas ed., Springfield, 1945; b) Ruptures of the Kotator Cuff. Ch. Thomas ed., Springfield, 1952. 10. Patterson, R. L.; Darrach, W. - 'Ireatment of acute bursitis by needle irrigation. J. Bone a. Joint surg., 19:993-1002, 1937. 11. Steen, O. T.; McCullough, J. A. L. - Supra-spinatus tendinitis: survey of 300 consecutive cases treated by roentgentherapy. Am. J. Roentgenol., 65:245-254 (fevereiro) 1951. 12. Lippmann, R. K'. - Frozen shoulder; periarthritis; brcipital tenosynovitis. Arch. Surg., 47:283-296 (setembro) 1943. 13. Hitcheock, H. H.; Bechtol, C. O. - Painful shoulder. J. Bone a. Joint Surg., 30-A:263-273 (abril) 1948. 14. Withers, R. J. W. - The painful shoulder. J. Bone a. Joint Surg., 31-B:414-417 (agôsto) 1949. 15. Simmonds, F. A. - Shoulder pain. J. Bone a. Joint Surg., 31-B:426-432 (agôsto) 1949. 